\title{
The role of the arginine metabolome in pain: implications for sickle cell disease
}

This article was published in the following Dove Press journal:

Journal of Pain Research

30 March 2016

Number of times this article has been viewed

\begin{abstract}
Nitya Bakshi ${ }^{1-2}$
Claudia R Morris ${ }^{3-6}$

'Division of Pediatric HematologyOncology, Department of Pediatrics, Emory University School of Medicine, Atlanta, GA, USA $;{ }^{2}$ Aflac Cancer and Blood Disorders Center, Children's Healthcare of Atlanta, Atlanta, GA, USA; ${ }^{3}$ Division of Pediatric Emergency Medicine, Department of Pediatrics, Emory University School of Medicine, Atlanta, GA, USA; ${ }^{4}$ Department of Emergency Medicine, Emory University School of Medicine, Atlanta, GA, USA; 'Emory-Children's Center for Cystic Fibrosis and Airways Disease Research, Emory University School of Medicine, Atlanta, GA, USA; ${ }^{6}$ Pediatric Emergency Medicine, Children's Healthcare of Atlanta, Atlanta, GA, USA
\end{abstract}

Abstract: Sickle cell disease (SCD) is the most common hemoglobinopathy in the US, affecting approximately 100,000 individuals in the US and millions worldwide. Pain is the hallmark of SCD, and a subset of patients experience pain virtually all of the time. Of interest, the arginine metabolome is associated with several pain mechanisms highlighted in this review. Since SCD is an arginine deficiency syndrome, the contribution of the arginine metabolome to acute and chronic pain in SCD is a topic in need of further attention. Normal arginine metabolism is impaired in SCD through various mechanisms that contribute to endothelial dysfunction, vaso-occlusion, pulmonary complications, risk of leg ulcers, and early mortality. Arginine is a semiessential amino acid that serves as a substrate for protein synthesis and is the precursor to nitric oxide (NO), polyamines, proline, glutamate, creatine, and agmatine. Since arginine is involved in multiple metabolic processes, a deficiency of this amino acid has the potential to disrupt many cellular and organ functions. NO is a potent vasodilator that is depleted in SCD and may contribute to vaso-occlusive pain. As the obligate substrate for NO production, arginine also plays a mechanistic role in SCD-related pain, although its contribution to pain pathways likely extends beyond NO. Low global arginine bioavailability is associated with pain severity in both adults and children with SCD as well as other non-SCD pain syndromes. Preliminary clinical studies of arginine therapy in SCD demonstrate efficacy in treating acute vaso-occlusive pain, as well as leg ulcers and pulmonary hypertension. Restoration of arginine bioavailability through exogenous supplementation of arginine is, therefore, a promising therapeutic target. Phase II clinical trials of arginine therapy for sickle-related pain are underway and a Phase III randomized controlled trial is anticipated in the near future.

Keywords: arginine, arginase, sickle cell disease, pain, global arginine bioavailability ratio, nitric oxide

\section{Introduction}

Sickle cell disease (SCD) is the most common hemoglobinopathy in the US. It is estimated that approximately 100,000 individuals in the US have $\mathrm{SCD}^{1}$ although millions are affected worldwide. In hemoglobin $\mathrm{S}(\mathrm{HbS})$, glutamic acid is substituted by valine at the sixth position of the $\beta$-globin. SCD may be due to a homozygous $\mathrm{HbS}$ state (HbSS) or coinheritance of $\mathrm{HbS}$ with other hemoglobin mutations such as beta ${ }^{0}$ thalassemia (HbS-beta ${ }^{0}$ thal), HbC (HbSC), or beta ${ }^{+}$thalassemia mutations (HbS-beta thal). The sickle hemoglobin mutation results in intracellular polymerization of the deoxygenated hemoglobin molecules under hypoxic conditions. Intracellular polymer increases erythrocyte rigidity and ultimately damages and distorts the erythrocyte membrane producing a rigid "sickled" red blood cell with altered rheological and adhesive
Correspondence: Claudia R Morris Division of Pediatric Emergency Medicine, Department of Pediatrics, Emory University School of Medicine, 1760 Haygood Drive NE, W458, Atlanta, GA 30322, USA

Tel +l 4047275500

Email claudia.r.morris@emory.edu; claudiamorris@comcast.net
Journal of Pain Research 2016:9 167-175

167

Dovepress

http://dx.doi.org/1 0.2147/JPR.S5557| (c) (1) (5) 2016 Bakshi and Morris. This work is published and licensed by Dove Medical Press Limited. The full terms of this license are available at https://www.dovepress.com/ cc) ${ }_{\mathrm{BY}} \mathrm{NC}$ terms.php and incorporate the Creative Commons Attribution - Non Commercial (unported, v3.0) License (httrp://creativecommons.org/licenses/lyy-nc/3.0/). By accessing the work you hereby accept the Terms. Non-commercial uses of the work are permitted without any further permission from Dove Medical Press Limited, provided the work is properly attributed. For permission for commercial use of this work, please see paragraphs 4.2 and 5 of our Terms (https://www.dovepress.com/terms.php). 
properties that becomes entrapped in the microcirculation and gives rise to the vaso-occlusive events characteristic of the disease. ${ }^{2,3}$

The clinical phenotype of SCD varies widely, depending on the genotype and even among patients with the same genotype. The clinical manifestations of SCD include anemia, episodes of severe vaso-occlusive pain, and other complications such as stroke, transient ischemic attacks, acute chest syndrome, splenic sequestration, and increased risk of bacterial sepsis. SCD can also result in end-organ damage in the central nervous system, lungs, and kidneys. A subset of patients with $\mathrm{SCD}$ also experience pain virtually all of the time. ${ }^{4}$

Vaso-occlusive painful episodes (VOE) are the hallmark of SCD. These painful episodes are the most common reason for hospitalization and result in significant morbidity. Hospitalization rates are particularly high for children with SCD, with hospitalization rates $>60 \%$ in one study. ${ }^{5}$ Hospitalizations for VOE are associated with high health-care costs, and sickle cell pain episodes contribute to costly readmissions. ${ }^{6}$ Pharmacologic treatment of painful vaso-occlusive episodes in the hospital setting includes hydration, intravenous opioids, and/or nonsteroidal anti-inflammatory drugs. There is no effective therapy that targets the underlying mechanisms of sickle-related pain. Treatment is largely symptomatic and has not changed substantially for decades. Additional supportive therapies such as rest, heat, and massage are also used in the management of SCD. ${ }^{7}$ More recently, several targeted novel therapies are or have been studied for the management of acute vaso-occlusive pain, including rivipansel (GMI-1070), ${ }^{8}$ intravenous magnesium, ${ }^{9,10}$ polaxamer- $188,{ }^{11}$ inhaled nitric oxide, ${ }^{12}$ lidocaine, ${ }^{13}$ low-molecular-weight heparin, ${ }^{14}$ and arginine. ${ }^{15}$ This review focuses on the role of arginine in pain pathways and its use for the treatment of SCD-associated pain. SCD is an arginine deficiency syndrome. ${ }^{16,17}$ Normal arginine metabolism is impaired through various mechanisms (Figure 1) that contribute to endothelial dysfunction, vaso-occlusion, pulmonary complications, risk of leg ulcers, and early mortality. ${ }^{18,19}$ Since low global arginine bioavailability is associated with a growing number of SCD-related complications, ${ }^{17,20}$ arginine therapy represents a promising option for SCD. ${ }^{18}$

Arginine is a semiessential cationic amino acid involved in multiple pathways in health and disease. It becomes essential, however, under conditions of stress and catabolic states when the capacity of endogenous arginine synthesis is exceeded, including trauma, sepsis, burns, and in conditions such as SCD and thalassemia. ${ }^{17,19,21}$ Arginine serves as a substrate for protein synthesis and is the precursor to nitric oxide (NO), polyamines, proline, glutamate, creatine, and agmatine. Arginine is derived from dietary protein intake, body protein breakdown, or endogenous de novo arginine production in the kidneys. Since it is involved in multiple metabolic processes, an arginine deficiency has the potential to disrupt many cellular and organ functions ${ }^{16} \mathrm{NO}$ is a potent vasodilator found to be deficient in $\mathrm{SCD}^{22-29}$ and is produced in the endothelium from its obligate substrate L-arginine. The SCD-related NO deficiency is a phenomenon linked to the process of hemolysis where cell-free hemoglobin is released from the erythrocyte ${ }^{30}$ and rapidly reacts with and consumes NO, while erythrocyte arginase, an L-argininemetabolizing enzyme, rapidly consumes the obligate substrate for NO production. ${ }^{17,31}$ Low NO in SCD likely plays a role in vasoconstriction, theoretically linking its depletion to vaso-occlusive pain. NO has been demonstrated as a signaling molecule in the nervous system as well as in nociceptive processing though its effects are undoubtedly complex as NO has been described to have both pro- and antinociceptive effects. ${ }^{32}$ In addition to its role in nociception, NO also has been implicated in opioid tolerance and dependence. ${ }^{33,34}$ Paradoxically, however, low levels of $\mathrm{NO}^{22,35,36}$ and its substrate L-arginine are found in adults and children with SCD during vaso-occlusive pain events, ${ }^{22,37}$ and correlate with pain severity. ${ }^{35}$ Further, arginine supplementation has been shown to decrease total opioid use and improve pain scores in children with SCD admitted to the hospital for inpatient treatment of pain. ${ }^{15}$ In sum, conflicting data on the role of the arginine-NO pathway in pain mechanisms, particularly in SCD, beg further study and elucidation.

\section{Arginine in sickle cell disease}

Approximately 2-7 g of L-arginine is ingested daily in a normal Western diet. Common dietary sources are meat, poultry, nuts, fish, and watermelon. It is also a safe nutritional supplement that has been studied in human and animal trials, including a growing number of trials in SCD. ${ }^{18}$

Adults with SCD are arginine deficient at steady state ${ }^{22,38,39}$; however, children have plasma levels that are similar to normal controls. ${ }^{22}$ An arginine deficiency develops over time and is influenced by acute events. ${ }^{22} \mathrm{~A}$ state of a low global arginine bioavailability occurs in SCD that goes beyond the concentration of arginine in plasma. To better assess arginine bioavailability for intracellular function, the "global arginine bioavailability ratio" (GABR) was established, defined as ratio of arginine over ornithine plus citrulline. ${ }^{17}$ This ratio takes into account the impact of arginase activity metabolizing arginine 


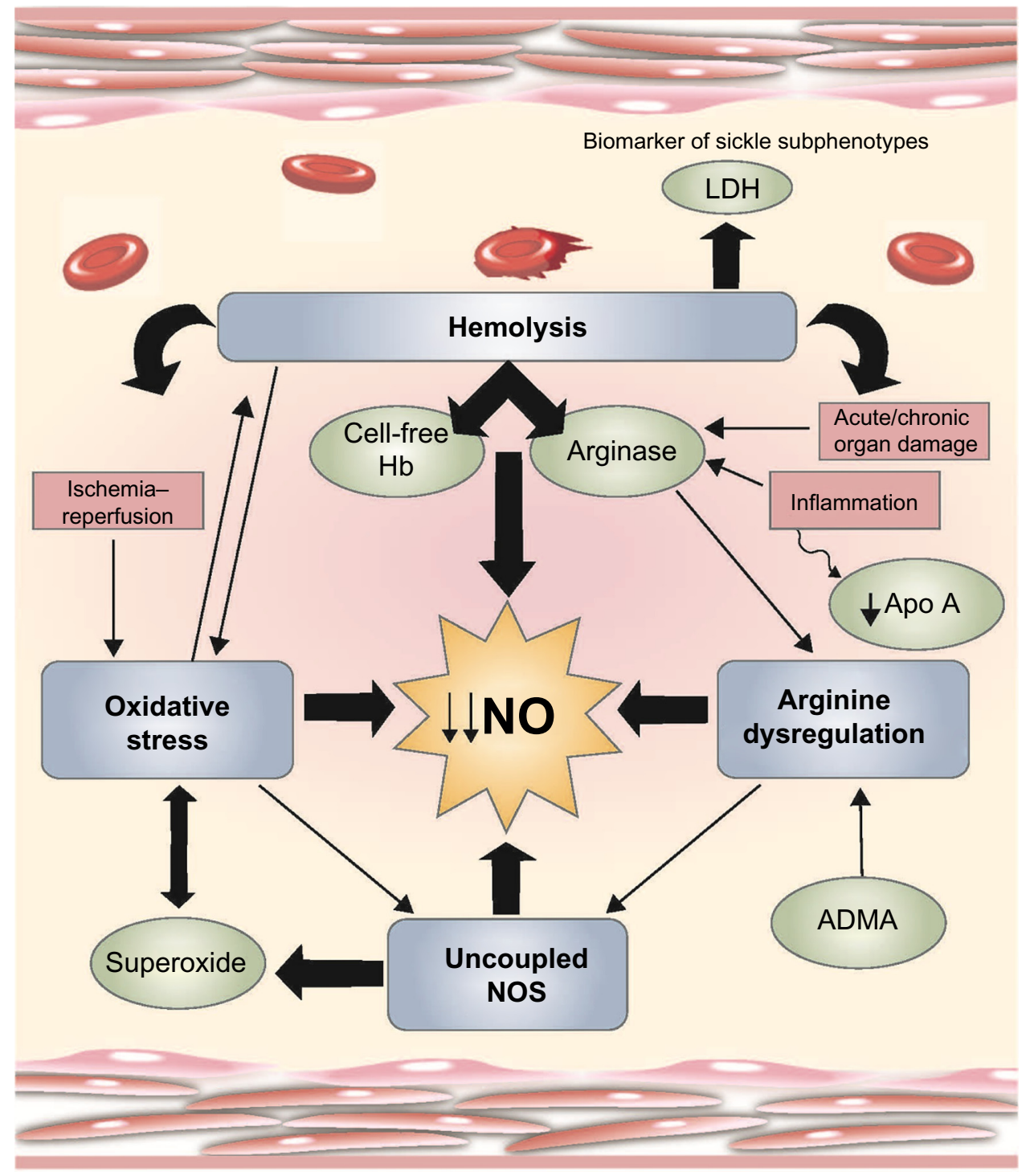

Figure I Mechanisms of vasculopathy in SCD.

Notes: Hemolysis, arginine dysregulation, oxidative stress, uncoupled NO synthases (NOS), and damage from redox-active heme are key mechanisms that contribute to the complex vascular pathophysiology of SCD. These events limit NO bioavailability through several paths that ultimately provoke increased consumption and decreased production of the potent vasodilator, NO. During hemolysis, cell-free hemoglobin and arginase are simultaneously released from the erythrocyte and profoundly contribute to low NO bioavailability. LDH is also released from the erythrocyte and represents a convenient biomarker of hemolysis that delineates the subphenotypes of SCD. Republished with permission of the American Society of Hematology, from Mechanisms of vasculopathy in sickle cell disease and thalassemia, Morris CR, Hematology Am Soc Hematol Educ Program. 2008;2008: 177-185, Copyright (C) 2008; permission conveyed through Copyright Clearance Center, Inc. ${ }^{19}$

Abbreviations: SCD, sickle cell disease; NO, nitric oxide; LDH, lactate dehydrogenase; Hb, hemoglobin; ADMA, elevated asymmetric dimethylarginine.

to ornithine, amino acid competition for intracellular transport by ornithine, and renal dysfunction reflected by accumulation of plasma citrulline. ${ }^{17}$ Low GABR is associated with pulmonary hypertension risk in both $\mathrm{SCD}^{17,40}$ and thalassemia ${ }^{21}$ and increased mortality in SCD. ${ }^{17,20}$ Interestingly, GABR is also low in diabetes, ${ }^{41}$ and has been shown to be a strong predictor of cardiovascular disease and early mortality in general, ${ }^{42-44}$ suggesting an important role for arginine bioavailability for survival that goes beyond SCD. Arginine also alters the effect of hydroxyurea, ${ }^{45,46}$ a disease-modifying US Food and Drug Administration-approved therapy in patients with
SCD. Patients with SCD who receive hydroxyurea along with arginine show an acute increase in NO metabolite levels even at steady state, ${ }^{45,46}$ not seen with arginine alone. ${ }^{45,47}$ Arginine butyrate has also been shown to improve healing of refractory leg ulcers in a randomized, Phase II placebo-controlled trial of patients with $\mathrm{SCD} .^{48}$

There are several elements of arginine dysregulation in SCD that can impact its bioavailability. With low plasma arginine levels even at steady state often well below the affinity constant $\left(K_{\mathrm{m}}\right)$ for the cationic acid transporter responsible for intracellular arginine uptake, even modest fluctuations in 
extracellular arginine concentration may significantly impact cellular arginine uptake and bioavailability. In addition, ornithine and lysine use the same cationic acid transporter protein for intracellular transport. High concentrations of these amino acids will competitively inhibit intracellular arginine transport. ${ }^{18}$ Therefore, a low GABR impacts arginine bioavailability and uptake. In addition, there is increased catabolism of arginine in SCD. Arginase is a urea cycle enzyme that catalyzes the hydrolysis of L-arginine to urea and L-ornithine. Arginase competes with NO synthases for their common substrate L-arginine. Plasma arginase concentration and activity are elevated in SCD as a consequence of inflammation, liver dysfunction, and, most significantly, by the release of erythrocyte arginase during intravascular hemolysis, which has been demonstrated by the strong correlation between plasma arginase levels and cell-free hemoglobin levels ${ }^{17}$ together with other markers of increased hemolytic rate including lactate dehydrogenase. ${ }^{17,40}$ Whether inflammatory or hemolytic in origin, arginase will redirect the metabolism of arginine away from NO to ornithine and the formation of polyamines and proline (Figure 2). ${ }^{17,19}$ An arginine deficiency in SCD is associated with elevated arginase activity and a low arginine-ornithine ratio ${ }^{31}$ that correlates to markers of hemolysis. ${ }^{17,18,40}$ Low global arginine bioavailability may be exacerbated further by the presence of elevated asymmetric dimethylarginine (ADMA), which is a competitive inhibitor of arginine transport and all NOS isozymes. Circulating ADMA levels are elevated in several conditions of endothelial dysfunction, including SCD, ${ }^{49}$ and are also associated with increased mortality. ${ }^{50}$

\section{Arginine in pain}

Low levels of plasma L-arginine and low GABR have been reported in patients with complex regional pain syndrome (CRPS); patients were noted to have lower levels as compared to controls. ${ }^{51}$ However, this finding was not corroborated in another study carried out in CRPS patients by Wesseldijk et al, ${ }^{52}$ where arginine levels were increased in patients with CRPS as compared to controls. The role of arginine in influencing pain sensitivity is not clear, but it is emerging as a mechanism of interest. In an animal model, arginine was shown to increase pain sensitivity. ${ }^{53}$ Clinical trials of arginine in painful human conditions have produced contradictory findings. In some studies, local

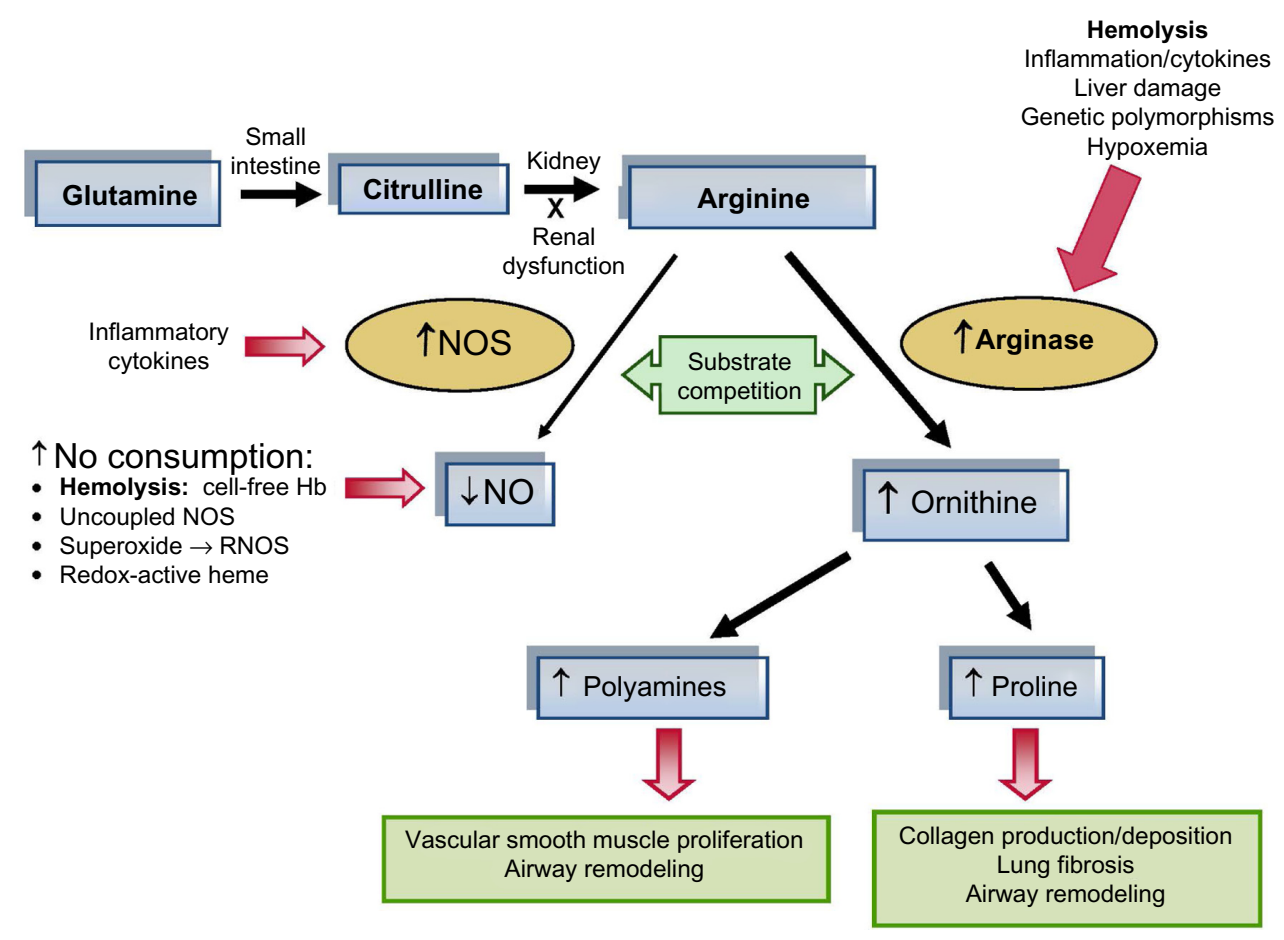

Figure 2 Altered arginine metabolism in hemolysis.

Notes: Dietary glutamine serves as a precursor for the de novo production of arginine through the citrulline-arginine pathway. Arginine is synthesized endogenously from citrulline primarily via the intestinal-renal axis. Arginase and NO synthases (NOS) compete for arginine, their common substrate. In SCD, bioavailability of arginine and NO is decreased by several mechanisms linked to hemolysis and oxidative stress. Endothelial dysfunction resulting from NO depletion and increased levels of the downstream products of ornithine metabolism (polyamines and proline) likely contribute to the pathogenesis of lung injury, fibrosis, and pulmonary hypertension. This disease paradigm has implications for all hemolytic processes. "X" means kidney dysfunction, or a block in the conversion of citrulline to arginine in the kidney. Copyright $(2008$ by the American Republished with permission of the American Society of Hematology, from Mechanisms of vasculopathy in sickle cell disease and thalassemia, Morris CR, Hematology Am Soc Hematol Educ Program. 2008;2008: 177-185, Copyright @ 2008; permission conveyed through Copyright Clearance Center, Inc. ${ }^{19}$

Abbreviations: NO, nitric oxide; NOS, nitric oxide synthases; SCD, sickle cell disease; Hb, hemoglobin. 
arginine application in combination with calcium carbonate has been shown to be beneficial in the treatment of dentine hypersensitivity, ${ }^{54-56}$ although the mechanism is related to physical sealing of dentin tubules with a plug that is resistant to pulpal pressures and acid challenge. ${ }^{57}$ Ibuprofen arginate, a salt of ibuprofen combined with arginine, has been used in the treatment of painful conditions such as primary dysmenorrhea, ${ }^{58}$ migraine, ${ }^{59}$ and periodontitis. ${ }^{60}$ In this context it is difficult, however, to determine the contribution of arginine per se in pain relief as it is combined with ibuprofen. In two randomized, placebo-controlled trials, ibuprofen arginate was found to be superior to ibuprofen in the time to achieve postoperative dental pain relief. This is attributed to the increased bioavailability and absorption of the ibuprofen arginate salt as opposed to conventional ibuprofen. ${ }^{61,62}$ The ibuprofen-arginine formulation is also thought to have a faster absorption profile. However, De Palma et $\mathrm{al}^{63}$ have described increase in bioactive NO with administration of ibuprofen arginate in an epithelial cell-culture model and decreased inflammation with ibuprofen-arginine after joint injury in a mouse model as compared to ibuprofen or arginine alone, suggesting synergy. In addition to enhancing the anti-inflammatory effect of ibuprofen, the authors also noted that anti-inflammatory effect was seen with arginine alone, thereby suggesting that NO generation contributed to the enhanced inflammatory effect. ${ }^{63}$ Interestingly, in a study measuring NO metabolites after ibuprofen-arginine administration in patients with chronic low back pain, the authors noted a decrease in NO metabolite levels following ibuprofen-arginine administration, and this was postulated to be secondary to ibuprofen. ${ }^{64}$ However, a paradoxical decrease in NO metabolites has also been described after a single dose of oral arginine supplementation in SCD, while NO metabolites increase when the same dose is given during an acute pain episode. ${ }^{47}$ This suggests differences in arginine metabolism that are dependent on the clinical state of the individual. Arginine supplementation has also demonstrated an anti-inflammatory and antioxidant effect on SCD in both animal models ${ }^{65-68}$ and human studies. ${ }^{69}$

It has been suggested in one study that administration of oral arginine decreases the frequency and intensity of chest pain attacks in esophageal spastic disorders. ${ }^{70}$ Other small studies with a very limited number of patients have also suggested some benefit of L-arginine in pain. In a study with 12 chronic pain patients of diverse etiologies, an intravenous infusion of L-arginine resulted in analgesia, with the effect lasting 6-24 hours. ${ }^{71,72}$ In another small study of patients with interstitial cystitis receiving L-arginine, a small improvement in pain intensity but not pain frequency was reported. ${ }^{73}$

\section{Agmatine - an arginine metabolite with a role in pain}

Interestingly, several small studies have utilized agmatine (decarboxylated arginine that is metabolized from L-arginine by the enzyme arginine decarboxylase in the mammalian brain) as a neuroprotective agent; one study showed improvement in symptoms of lumbar radiculopathy and pain with supplementation with agmatine, although more than a third of the participants in this study were excluded from analysis for various reasons. ${ }^{74}$ In animal models, agmatine has been shown to decrease tactile and thermal allodynia as well as mechanical hyperalgesia in diabetic rats but not in healthy rats. A similar result was seen in an animal model of chronic constriction nerve injury where agmatine produced an anti-allodynic effect and in mouse models of chemical or mechanical injury where it decreased hyperalgesia. ${ }^{75,76}$ Agmatine is thought to exert its effects via the imidazoline receptors, and has been shown in animal models to enhance morphine analgesia when given centrally. ${ }^{77,78}$ Agmatine may also attenuate opioid tolerance; however, efforts to increase endogenous agmatine by administration of L-arginine have been successful only when given centrally but not systemically. ${ }^{77,78}$

\section{Asymmetric dimethyl arginine - an arginine analog with a role in pain}

ADMA is a methylated arginine that competes for the arginine binding site of NO synthase and functions as a competitive NO synthase inhibitor. Known for its role as a biomarker of cardiovascular disease, ${ }^{79}$ recent studies implicate it in pain mechanisms.$^{80}$ In patients with osteoarthritis (OA) scheduled to undergo knee replacement, plasma arginine concentrations were lower in the OA patients than in controls, while plasma ADMA concentrations were similar. Accordingly, the arginine/ADMA ratio was lower in the OA patients than in the control group, but the relationship of these biomarkers with pain is unclear. ${ }^{81}$ Elevated arginase levels have been reported in rheumatoid arthritis. ${ }^{82}$ More recently, increased ADMA levels have been reported in ankylosing spondylitis. While these have correlated with markers of disease activity, they have not been correlated specifically with pain scores. ${ }^{83,84}$ Increased ADMA levels have also been reported in migraine, both during headache and the interictal period. ${ }^{85}$ Increased ADMA levels have also been associated with primary dysmenorrhea ${ }^{86}$ Interestingly, in an animal model of renal failure, infusion of ADMA in healthy rats or in those with nephrectomy (inducing renal failure) resulted in increase of thermal pain threshold.$^{87}$ ADMA levels are also increased in $\mathrm{SCD}^{49}$ and will impact arginine bioavailability. It is unknown 
what role, if any, ADMA has on pain in SCD, but it will be evaluated in future studies.

\section{Kyotorphin - an L-arginine/L-tyrosine dipeptide with a role in pain}

Kyotorphin is an endogenous antinociceptive dipeptide synthesized from L-arginine and L-tyrosine by kyotorphin synthase in an ATP-Mg(2+)-dependent manner. ${ }^{88}$ It was first isolated by Takagi et al $^{89}$ in 1979 from the bovine brain. It has been isolated from the human central nervous system and Nishimura et $\mathrm{al}^{90}$ reported that lower levels of kyotorphin were reported in cerebrospinal fluid from patients with persistent pain. Kyotorphin exerts its antinociceptive effect via Met-enkephalin release. ${ }^{88,91}$ Interestingly, central (intracerebroventricular or intracisternal) injection of L-arginine produces antinociception in mice. ${ }^{92,93}$ In a diabetic mouse model, antinociception produced by L-arginine was greater in diabetic mice than in nondiabetic mice. ${ }^{94}$ Kyotorphin does not cross the blood-brain barrier ${ }^{95}$ and therefore has not been exploited as an analgesic; however, derivatives of kyotorphin that can cross the bloodbrain barrier are now being studied as analgesics. ${ }^{96}$

\section{Arginine in sickle cell vaso-occlusive pain episodes}

Plasma arginine concentration decreases acutely in both adults and children during episodes of vaso-occlusive pain and is associated with low NO metabolite levels, ${ }^{22,37,47}$ with both arginine and NO metabolite levels returning to baseline during recovery. Low plasma arginine levels predicted clinical need for admission in children with SCD and pain presenting for emergency care, while NO metabolite levels did not, ${ }^{22}$ suggesting a role for arginine bioavailability during pain events that goes beyond NO production. Other potential mechanisms that have already been discussed become interesting targets for further evaluation in order to better understand the role of arginine dysregulation in VOE.

Since an acute arginine deficiency and low NO bioavailability develops during VOE, it is intuitive to explore the potential of arginine supplementation as a potential new treatment for sickle-related pain. Morris et $\mathrm{al}^{15}$ have reported the results of a single-center randomized, double-blinded, placebo-controlled trial of arginine therapy in children with SCD and pain requiring hospitalization. Thirty-eight children with SCD admitted for 56 episodes of VOE were randomized to receive oral or parenteral L-arginine (100 mg/kg three times per day) or placebo for 5 days or until discharge. A significant reduction in total parenteral opioid use by $54 \%(1.9 \pm 2.0 \mathrm{vs} 4.1 \pm 4.1 \mathrm{mg} / \mathrm{kg}, P=0.02)$ and lower pain scores at discharge $(1.9 \pm 2.4$ vs $3.9 \pm 2.9, P=0.01)$ were observed in those receiving arginine compared with those receiving placebo (Figure 3). While there was a clinically relevant trend toward shorter duration of hospital stay among those receiving arginine, this did not achieve statistical significance $(4.1 \pm 1.8$ vs $4.8 \pm 2.5$ days, $P=0.34)$. Total opioid use correlated strongly to length of admission ( $r=0.86, P<0.0001$, Figure 4). Delivering arginine therapy as early as possible in the emergency department or clinic may have a greater impact on time to pain crisis resolution, because many patients in the abovementioned arginine study received their first dose of study medication more than 24 hours after presenting to the emergency department in pain. ${ }^{15}$ No drug-related adverse events were observed. No clinical deterioration or pediatric intensive care unit transfers occurred in the arginine arm. ${ }^{15}$
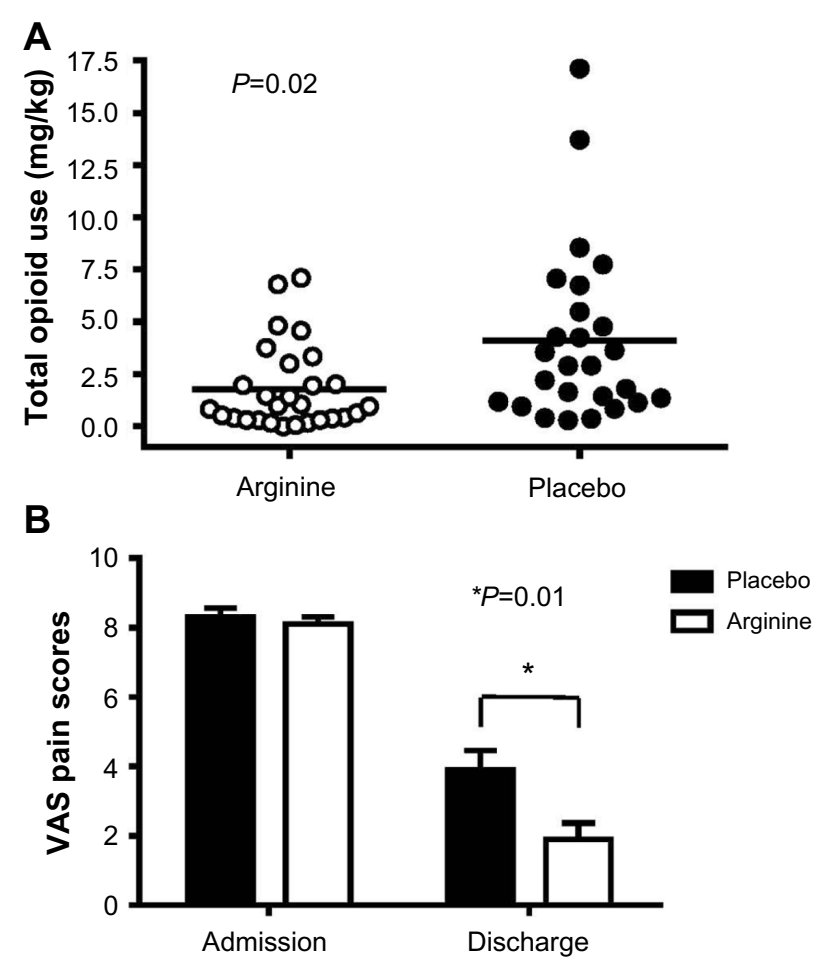

Figure 3 Impact of arginine therapy on total opioid use $(\mathrm{mg} / \mathrm{kg})$ and pain scores in children with SCD hospitalized for vaso-occlusive pain.

Notes: (A) Arginine supplementation (unfilled circles) led to a significant and clinically relevant reduction in total opioid use by $54 \%$ over the course of the hospital stay compared to total opioid use in the placebo group (filled circles). The difference remains significant even when the two outliers with the largest total opioid use in the placebo arm are excluded from the analysis $(P=0.04)$. (B) I0-cm VAS pain scores were similar at the time of admission in both groups, but were significantly lower at discharge in the arginine group compared to placebo by $2 \mathrm{~cm}(P=0.01)$. Copyright (C) 2013 Ferrata Storti Foundation. Reproduced with permission from Morris CR, Kuypers FA, Lavrisha L, et al. A randomized, placebo-controlled trial of arginine therapy for the treatment of children with sickle cell disease hospitalized with vasoocclusive pain episodes. Haematologica. 2013;98(9):1375-1382. ${ }^{15}$

Abbreviations: SCD, sickle cell disease; VAS, visual analog scale. 


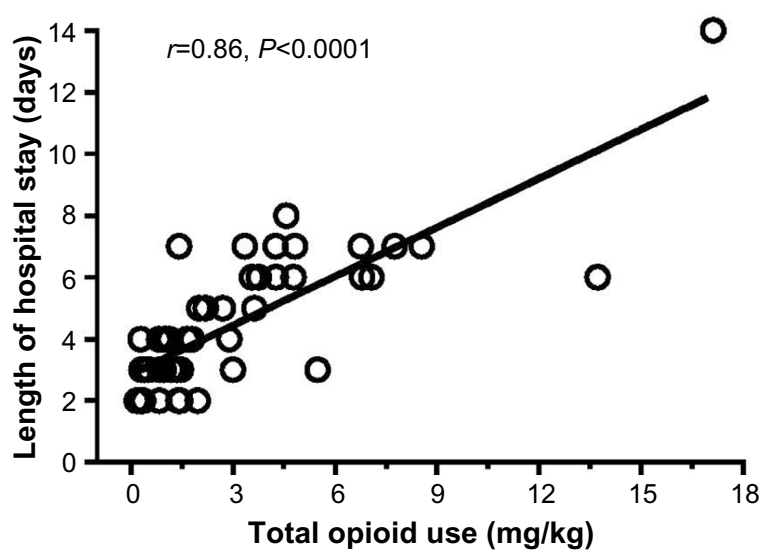

Figure 4 Pearson correlation between total opioid use $(\mathrm{mg} / \mathrm{kg})$ and total length of hospital stay (days).

Notes: Total opioid use $(\mathrm{mg} / \mathrm{kg})$ is directly correlated to length of hospital stay $(r=0.86, P<0.000 \mathrm{I})$. Total opioid use may be a surrogate for length of hospital stay as an outcome measure for patients with SCD and pain. Copyright (C) 2013 Ferrata Storti Foundation. Reproduced with permission from Morris CR, Kuypers FA, Lavrisha $L$, et al. A randomized, placebo-controlled trial of arginine therapy for the treatment of children with sickle cell disease hospitalized with vaso-occlusive pain episodes. Haematologica. 2013;98(9): 1375-1382. ${ }^{15}$

Abbreviation: SCD, sickle cell disease.

\section{Conclusion}

A growing body of data implicates the arginine-NO pathway in pain, although mixed results have been reported on the role of a deficiency versus excess. Low arginine bioavailability is the more likely culprit in $\mathrm{SCD}^{19}$ and contributes to acute pain, endothelial dysfunction, pulmonary complications, risk of leg ulcers, and early mortality. ${ }^{18,19}$ An altered arginine metabolome in some pain syndromes is intriguing and suggests the potential for shared mechanisms in SCD with other chronic pain conditions that are to date not well characterized. An arginine deficiency can be overcome through arginine supplementation. Promising data from Phase II randomized controlled trials for treatment of chronic refractory leg ulcers ${ }^{48}$ and vaso-occlusive pain in patients with $\mathrm{SCD}^{15}$ support the need for further investigation. Since low global arginine bioavailability is associated with a growing number of SCD-related complications, ${ }^{17,20}$ arginine therapy represents a promising option for SCD. ${ }^{18}$ Clinical trials of arginine therapy targeting vaso-occlusive pain are underway. Further investigation into the role of global arginine bioavailability in pain syndromes beyond SCD is warranted.

\section{Disclosure}

Nitya Bakshi has received funding from the Sickle Cell Disease Association of America Research Scholar Program. Claudia R Morris, is the inventor or coinventor of several Children's Hospital and Research Center Oakland patents/ patent-pending applications that include biomarkers of cardiovascular disease related to arginine bioavailability, is an inventor of an Emory University School of Medicine patent application for a nutritional supplement, is a consultant for Pfizer, NourishLife, LLC, and Calithera Biosciences, Inc., and has received research support from MAST Therapeutics, the United States Food and Drug Administration, and the National Institutes of Health. The authors report no other conflicts of interest in this work.

\section{References}

1. Hassell KL. Population estimates of sickle cell disease in the U.S. Am J Prev Med. 2010;38(4 Supp1):S512-S521.

2. Stuart MJ, Nagel RL. Sickle cell disease. Lancet. 2004;364(9442): 1343-1360.

3. Gladwin MT, Vichinsky E. Pulmonary complications of sickle cell disease. N Engl J Med. 2008;359(21):2254-2265.

4. Smith WR, Penberthy LT, Bovbjerg VE, et al. Daily assessment of pain in adults with sickle cell disease. Ann Intern Med. 2008;148(2):94-101.

5. Frei-Jones MJ, Baxter AL, Rogers ZR, et al. Vaso-occlusive episodes in older children with sickle cell disease: emergency department management and pain assessment. J Pediatr. 2008;152(2):281-285.

6. Gay JC, Agrawal R, Auger KA, et al. Rates and impact of potentially preventable readmissions at children's hospitals. J Pediatr. 2015;166(3):613-619.e5.

7. Lemanek KL, Ranalli M, Lukens C. A randomized controlled trial of massage therapy in children with sickle cell disease. J Pediatr Psychol. 2009;34(10):1091-1096.

8. Wun T, Telen MJ, Krishnamurti L, et al. Pan-selectin antagonist rivipansel (GMI-1070) reduces soluble E-selectin levels while improving clinical outcomes in SCD vaso-occlusive crisis. Blood. 2014;124(21):2704.

9. Badaki-Makun O, Scott JP, Panepinto JA, et al. Intravenous magnesium for pediatric sickle cell vaso-occlusive crisis: methodological issues of a randomized controlled trial. Pediatr Blood Cancer. 2014;61(6):1049-1054.

10. Brousseau DC, Scott JP, Hillery CA, et al. The effect of magnesium on length of stay for pediatric sickle cell pain crisis. Acad Emerg Med. 2004;11(9):968-972.

11. Gibbs WJ, Hagemann TM. Purified poloxamer 188 for sickle cell vasoocclusive crisis. Ann Pharmacother. 2004;38(2):320-324.

12. Gladwin MT, Kato GJ, Weiner D, et al. Nitric oxide for inhalation in the acute treatment of sickle cell pain crisis: a randomized controlled trial. JAMA. 2011;305(9):893-902.

13. Rasolofo J, Poncelet M, Rousseau V, et al. Analgesic efficacy of topical lidocaine for vaso-occlusive crisis in children with sickle cell disease. Arch Pediatr. 2013;20(7):762-767.

14. van Zuuren EJ, Fedorowicz Z. Low-molecular-weight heparins for managing vasoocclusive crises in people with sickle cell disease: a summary of a cochrane systematic review. Hemoglobin. 2014;38(3): 221-223.

15. Morris CR, Kuypers FA, Lavrisha L, et al. A randomized, placebocontrolled trial of arginine therapy for the treatment of children with sickle cell disease hospitalized with vaso-occlusive pain episodes. Haematologica. 2013;98(9):1375-1382.

16. Morris SM Jr. Arginases and arginine deficiency syndromes. Curr Opin Clin Nutr Metab Care. 2012;15(1):64-70.

17. Morris CR, Kato GJ, Poljakovic M, et al. Dysregulated arginine metabolism, hemolysis-associated pulmonary hypertension, and mortality in sickle cell disease. JAMA. 2005;294(1):81-90.

18. Morris CR. Alterations of the arginine metabolome in sickle cell disease: a growing rationale for arginine therapy. Hematol Oncol Clin North Am. 2014;28(2):301-321.

19. Morris CR. Mechanisms of vasculopathy in sickle cell disease and thalassemia. Hematology Am Soc Hematol Educ Program. 2008;2008: $177-185$. 
20. Cox SE, Makani J, Komba AN, et al. Global arginine bioavailability in Tanzanian sickle cell anemia patients at steady-state: a nested case control study of deaths versus survivors. Br J Haematol. 2011;155(4):522-524.

21. Morris CR, Kim HY, Klings ES, et al. Dysregulated arginine metabolism and cardiopulmonary dysfunction in patients with thalassaemia. $\mathrm{Br} \mathrm{J}$ Haematol. 2015;169(6):887-898.

22. Morris CR, Kuypers FA, Larkin S, et al. Patterns of arginine and nitric oxide in sickle cell disease patients with vaso-occlusive crisis and acute chest syndrome. J Pediatr Hematol Oncol. 2000;22:515-520.

23. Reiter CD, Wang X, Tanus-Santos JE, et al. Cell-free hemoglobin limits nitric oxide bioavailability in sickle cell disease. Nat Med. 2002;8:1383-1389.

24. Rother RP, Bell L, Hillmen P, et al. The clinical sequelae of intravascular hemolysis and extracellular plasma hemoglobin: a novel mechanism of human disease. JAMA. 2005;293:1653-1662.

25. Aslan M, Ryan TM, Adler B, et al. Oxygen radical inhibition of nitric oxide-dependent vascular function in sickle cell disease. Proc Natl Acad Sci USA. 2001;98(26):15215-15220.

26. Kaul DK, Liu XD, Fabry ME, et al. Impaired nitric oxide-mediated vasodilation in transgenic sickle mouse. Am J Physiol Heart Circ Physiol. 2000;278:H1799-H1806.

27. Eberhardt RT, McMahon L, Duffy SJ, et al. Sickle cell anemia is associated with reduced nitric oxide bioactivity in peripheral conduit and resistance vessels. Am J Hematol. 2003;74:104-111.

28. Gladwin MT, Schechter A, Ognibene F, et al. Divergent nitric oxide bioavailability in men and women with sickle cell disease. Circulation. 2003;107:271-278.

29. Belhassen L, Pelle G, Sediame S, et al. Endothelial dysfunction in patients with sickle cell disease is related to selective impairment of shear stress-mediated vasodilation. Blood. 2001;97:1584-1589.

30. Reiter CD, Gladwin MT. An emerging role for nitric oxide in sickle cell disease vascular homeostasis and therapy. Curr Opin Hematol. 2003;10(2):99-107.

31. Morris CR, Morris SM Jr, Hagar W, et al. Arginine therapy: a new treatment for pulmonary hypertension in sickle cell disease? Am J Respir Crit Care Med. 2003;168:63-69.

32. McMahon SB. Wall and Melzack's Textbook of Pain. 6th ed. Philadelphia, PA: Elsevier/Saunders; 2013:xxix, 1153pp.

33. Mayer DJ, Mao JR, Holt J, et al. Cellular mechanisms of neuropathic pain, morphine tolerance, and their interactions. Proc Natl Acad Sci US A. 1999;96(14):7731-7736.

34. Bhargava HN. Nitric-oxide synthase inhibition blocks tolerance to the analgesic action of kappa-opiate receptor agonist in the rat. Pharmacology. 1994;48(4):234-241.

35. Lopez BL, Davis-Moon L, Ballas SK, et al. Sequential nitric oxide measurements during the emergency department treatment of acute vasoocclusive sickle cell crisis. Am J Hematol. 2000;64(1): 15-19.

36. Lopez BL, Barnett J, Ballas SK, et al. Nitric oxide metabolite levels in acute vaso-occlusive sickle-cell crisis. Acad Emerg Med. 1996;3(12):1098-1103.

37. Lopez BL, Kreshak AA, Morris CR, et al. L-Arginine levels are diminished in adult acute vaso-occlusive sickle cell crisis in the emergency department. Br J Haematol. 2003;120:532-534.

38. Enwonwu CO. Increased metabolic demand for arginine in sickle cell anemia. Med Sci Res. 1989;17:997-998.

39. Waugh W, Daeschner C, Files B, et al. Evidence that L-arginine is a key amino acid in sickle cell anemia - a preliminary report. Nutr Res. 1999; 19:501-518.

40. Kato GJ, McGowan V, Machado RF, et al. Lactate dehydrogenase as a biomarker of hemolysis-associated nitric oxide resistance, priapism, leg ulceration, pulmonary hypertension, and death in patients with sickle cell disease. Blood. 2006;107(6):2279-2285.

41. Tripolt NJ, Meinitzer A, Eder M, et al. Multifactorial risk factor intervention in patients with Type 2 diabetes improves arginine bioavailability ratios. Diabet Med. 2012;29(10):e365-e368.
42. Tang WHW, Wang Z, Cho L, et al. Diminished global arginine bioavailability and increased arginine catabolism as metabolic profile of increased cardiovascular risk. J Am Coll Cardiol. 2009;53(22):2061-2067.

43. Erdely A, Kepka-Lenhart D, Salmen-Muniz R, et al. Arginase activities and global arginine bioavailability in wild-type and ApoE-deficient mice: responses to high fat and high cholesterol diets. PLoS One. 2010;5(12):e15253.

44. Sourij H, Meinitzer A, Pilz S, et al. Arginine bioavailability ratios are associated with cardiovascular mortality in patients referred to coronary angiography. Atherosclerosis. 2011;218(1):220-225.

45. Morris CR, Vichinsky EP, van Warmerdam J, et al. Hydroxyurea and arginine therapy: impact on nitric oxide production in sickle cell disease. $J$ Pediatr Hematol Oncol. 2003;25(8):629-634.

46. Elias DB, Barbosa MC, Rocha LB, et al. L-Arginine as an adjuvant drug in the treatment of sickle cell anemia. Br J Haematol. 2013;160(3):410-412.

47. Morris CR, Kuypers FA, Larkin S, et al. Arginine therapy: a novel strategy to increase nitric oxide production in sickle cell disease. $\mathrm{Br} J$ Haematol. 2000;111:498-500.

48. McMahon L, Tamary H, Askin M, et al. A randomized phase II trial of Arginine Butyrate with standard local therapy in refractory sickle cell leg ulcers. Br J Haematol. 2010;151(5):516-524.

49. Schnog JB, Teerlink T, van der Dijs FP, et al. Plasma levels of asymmetric dimethylarginine (ADMA), an endogenous nitric oxide synthase inhibitor, are elevated in sickle cell disease. Ann Hematol. 2005;84(5):282-286.

50. Kato GJ, Wang Z, Machado RF, et al. Endogenous nitric oxide synthase inhibitors in sickle cell disease: abnormal levels and correlations with pulmonary hypertension, desaturation, haemolysis, organ dysfunction and death. Br J Haematol. 2009;145(4):506-513.

51. Alexander GM, Reichenberger E, Peterlin BL, et al. Plasma amino acids changes in complex regional pain syndrome. Pain Res Treat. 2013;2013:742407.

52. Wesseldijk F, Fekkes D, Huygen FJ, et al. Increased plasma glutamate, glycine, and arginine levels in complex regional pain syndrome type 1 . Acta Anaesthesiol Scand. 2008;52(5):688-694.

53. Severyanova LA, Bobyntsev II, Kir'yanova NA, et al. Effects of L-arginine on various types of pain sensitivity. Bull Exp Biol Med. 2006;141(5):567-570.

54. Franca IL, Sallum EA, Do Vale HF, et al. Efficacy of a combined in-office/home-use desensitizing system containing $8 \%$ arginine and calcium carbonate in reducing dentin hypersensitivity: an 8-week randomized clinical study. Am J Dent. 2015;28(1):45-50.

55. Bal MV, Keskiner I, Sezer U, et al. Comparison of low level laser and arginine-calcium carbonate alone or combination in the treatment of dentin hypersensitivity: a randomized split-mouth clinical study. Photomed Laser Surg. 2015;33(4):200-205.

56. Hegde S, Rao BH, Kakar RC, et al. A comparison of dentifrices for clinical relief from dentin hypersensitivity using the Jay Sensitivity Sensor Probe. Am J Dent. 2013;26 Spec No B:29B-36B.

57. Lavender SA, Petrou I, Heu R, et al. Mode of action studies on a new desensitizing dentifrice containing $8.0 \%$ arginine, a high cleaning calcium carbonate system and 1450 ppm fluoride. Am J Dent. 2010;23 Spec No A:14A-19A.

58. Castelo-Branco C, Casals G, Haya J, et al. Efficacy and safety of ibuprofen arginine in the treatment of primary dysmenorrhoea. Clin Drug Investig. 2004;24(7):385-393.

59. Sandrini G, Franchini S, Lanfranchi S, et al. Effectiveness of ibuprofenarginine in the treatment of acute migraine attacks. Int J Clin Pharmacol Res. 1998;18(3):145-150.

60. Ettlin DA, Ettlin A, Bless K, et al. Ibuprofen arginine for pain control during scaling and root planing: a randomized, triple-blind trial. J Clin Periodontol. 2006;33(5):345-350.

61. Mehlisch DR, Ardia A, Pallotta T. A controlled comparative study of ibuprofen arginate versus conventional ibuprofen in the treatment of postoperative dental pain. J Clin Pharmacol. 2002;42(8): 904-911. 
62. Desjardins P, Black P, Papageorge M, et al. Ibuprofen arginate provides effective relief from postoperative dental pain with a more rapid onset of action than ibuprofen. Eur J Clin Pharmacol. 2002;58(6):387-394.

63. De Palma C, Di Paola R, Perrotta C, et al. Ibuprofen-arginine generates nitric oxide and has enhanced anti-inflammatory effects. Pharmacol Res. 2009;60(4):221-228.

64. Sprott H, Gay RE, Michel BA, et al. Influence of ibuprofen-arginine on serum levels of nitric oxide metabolites in patients with chronic low back pain - a single-blind, placebo controlled pilot trial (ISRCTN18723747) $J$ Rheumatol. 2006;33(12):2515-2518.

65. Archer DR, Stiles JK, Newman GW, et al. C-reactive protein and interleukin-6 are decreased in transgenic sickle cell mice fed a high protein diet. J Nutr. 2008;138(6):1148-1152.

66. Dasgupta T, Hebbel RP, Kaul DK. Protective effect of arginine on oxidative stress in transgenic sickle mouse models. Free Radic Biol Med. 2006;41(12):1771-1780.

67. Kaul DK, Zhang X, Dasgupta T, et al. Arginine therapy of transgenicknockout sickle mice improves microvascular function by reducing non-nitric oxide vasodilators, hemolysis, and oxidative stress. Am J Physiol Heart Circ Physiol. 2008;295(1):H39-H47.

68. Hsu LL, Champion HC, Campbell-Lee SA, et al. Hemolysis in sickle cell mice causes pulmonary hypertension due to global impairment in nitric oxide bioavailability. Blood. 2007;109:3088-3098.

69. Little JA, Hauser KP, Martyr SE, et al. Hematologic, biochemical, and cardiopulmonary effects of L-arginine supplementation or phosphodiesterase 5 inhibition in patients with sickle cell disease who are on hydroxyurea therapy. Eur J Haematol. 2009;82(4):315-321.

70. Bortolotti M, Brunelli F, Sarti P, et al., Clinical and manometric effects of L-arginine in patients with chest pain and esophageal motor disorders Ital J Gastroenterol Hepatol. 1997;29(4):320-324.

71. Takagi H, Harima A, Shimizu H. A novel clinical treatment of persistent pain with L-arginine. Eur J Pharmacol. 1990;183(4):1443.

72. Harima A, Shimizu H, Takagi H. Analgesic effect of L-arginine in patients with persistent pain. Eur Neuropsychopharmacol. 1991;1(4):529-533.

73. Korting GE, Smith SD, Wheeler MA, et al. A randomized double-blind trial of oral L-arginine for treatment of interstitial cystitis. $J$ Urol. 1999;161(2):558-565.

74. Keynan O, Mirovsky Y, Dekel S, et al. Safety and efficacy of dietary agmatine sulfate in lumbar disc-associated radiculopathy. An openlabel, dose-escalating study followed by a randomized, double-blind, placebo-controlled trial. Pain Med. 2010;11(3):356-368.

75. Aricioglu F, Korcegez E, Bozkurt A, et al. Effect of agmatine on acute and mononeuropathic pain. Ann NY Acad Sci. 2003;1009:106-115.

76. Fairbanks CA, Schreiber KL, Brewer KL, et al. Agmatine reverses pain induced by inflammation, neuropathy, and spinal cord injury. Proc Natl Acad Sci U S A. 2000;97(19):10584-10589.

77. Kolesnikov Y, Jain S, Pasternak GW. Modulation of opioid analgesia by agmatine. Eur J Pharmacol. 1996;296(1):17-22.

78. Wu N, Su RB, Li J. Agmatine and imidazoline receptors: their role in opioid analgesia, tolerance and dependence. Cell Mol Neurobiol. 2008;28(5):629-641.

79. Boger RH. Asymmetric dimethylarginine, and endogenous inhibitor of nitric oxide synthase, explains the "L-arginine paradox" and acts as a novel cardiovascular risk factor. $J$ Nutr. 2004;134(10):2842s-2847s.
80. Greco R, Ferrigno A, Demartini C, et al. Evaluation of ADMADDAH-NOS axis in specific brain areas following nitroglycerin administration: study in an animal model of migraine. $J$ Headache Pain. 2015;16(1):560.

81. Pascale V, Pascale W, Lavanga V, et al. L-Arginine, asymmetric dimethylarginine, and symmetric dimethylarginine in plasma and synovial fluid of patients with knee osteoarthritis. Med Sci Monit. 2013;19:1057-1062.

82. Huang LW, Chang KL, Chen CJ, et al. Arginase levels are increased in patients with rheumatoid arthritis. Kaohsiung J Med Sci. 2001;17(7):358-363.

83. Sari I, Kebapcilar L, Alacacioglu A, et al. Increased levels of asymmetric dimethylarginine (ADMA) in patients with ankylosing spondylitis. Intern Med. 2009;48(16):1363-1368.

84. Surdacki A, Martens-Lobenhoffer J, Wloch A, et al. Elevated plasma asymmetric dimethyl-L-arginine levels are linked to endothelial progenitor cell depletion and carotid atherosclerosis in rheumatoid arthritis. Arthritis Rheum. 2007;56(3):809-819.

85. Uzar E, Evliyaoglu O, Toprak G, et al. Increased asymmetric dimethylarginine and nitric oxide levels in patients with migraine. $J$ Headache Pain. 2011;12(2):239-243.

86. Akdemir N, Cinemre H, Bilir C, et al. Increased serum asymmetric dimethylarginine levels in primary dysmenorrhea. Gynecol Obstet Invest. 2010;69(3):153-156

87. Kielstein JT, Suntharalingam M, Perthel R, et al. Asymmetric dimethylarginine may mediate increased heat pain threshold in experimental chronic kidney disease. Nephrol Dial Transplant. 2012;27(3):899-902.

88. Kawabata A, Muguruma H, Tanaka M, et al. Kyotorphin synthetase activity in rat adrenal glands and spinal cord. Peptides. 1996;17(3):407-411.

89. Takagi H, Shiomi H, Ueda H, et al. Morphine-like analgesia by a new dipeptide, L-tyrosyl-L-arginine (Kyotorphin) and its analog. Eur $J$ Pharmacol. 1979;55(1):109-111.

90. Nishimura K, Kaya K, Hazato T, et al. Kyotorphin like substance in human cerebrospinal fluid of patients with persistent pain. Masui. 1991;40(11):1686-1690.

91. Kawabata A, Umeda N, Takagi H. L-Arginine exerts a dual role in nociceptive processing in the brain - involvement of the kyotorphinMet-enkephalin pathway and NO-cyclic GMP pathway. Br JPharmacol. 1993;109(1):73-79.

92. Kawabata A, Manabe S, Takagi H. Comparison of antinociception induced by supraspinally administered L-arginine and kyotorphin. Br J Pharmacol. 1994;112(3):817-822.

93. Kawabata A, Iwatsubo K, Takaya S, et al., Central antinociceptive effect of L-ornithine, a metabolite of L-arginine, in rats and mice. Eur J Pharmacol. 1996;296(1):23-31.

94. Kamei J, Iwamoto Y, Misawa M, et al. Antinociceptive effect of L-arginine in diabetic mice. Eur J Pharmacol. 1994;254(1-2):113-117.

95. Schroeder U, Sommerfeld P, Ulrich S, et al. Nanoparticle technology for delivery of drugs across the blood-brain barrier. J Pharm Sci. 1998;87(11):1305-1307

96. Ribeiro MM, Santos SS, Sousa DS, et al. Side effects of analgesic kyotorphin derivatives: advantages over clinical opioid drugs. Amino Acids. 2013;45(1):171-178.
Journal of Pain Research

\section{Publish your work in this journal}

The Journal of Pain Research is an international, peer-reviewed, open access, online journal that welcomes laboratory and clinical findings in the fields of pain research and the prevention and management of pain. Original research, reviews, symposium reports, hypothesis formation and commentaries are all considered for publication.

\section{Dovepress}

The manuscript management system is completely online and includes a very quick and fair peer-review system, which is all easy to use. Visit http://www.dovepress.com/testimonials.php to read real quotes from published authors. 